\title{
Çocukluk Çağı Beyin Tümörleri Deneyimimiz
}

\author{
Pediatric Central Nervous System Tumors: Center Experience \\ Bermal Hasbay $^{1^{\star}}$, Fazilet Kayaselçuk ${ }^{1}$, Özgür Kardeş ${ }^{2}$, Nalan Yazıcı ${ }^{3}$ \\ ${ }^{1}$ Başkent Üniversitesi Adana Dr. Turgut Noyan Uygulama ve Araştırma Merkezi, Patoloji Ana Bilim Dalı, Adana \\ ${ }^{2}$ Baskent Üniversitesi Adana Dr. Turgut Noyan Uygulama ve Araștırma Merkez̧i, Beyin Cerrabi Ana Bilim Dali, \\ Adana \\ ${ }^{3}$ Başkent Üniversitesi Adana Dr. Turgut Noyan Uygulama ve Araștırma Merkequi, Cocuk Onkoloji Ana Bilim Dalı, \\ Adana
}

\begin{abstract}
ÖZET
Amaç: Çalışmamızda hastanemizde beyin tümörü tanısı alan pediatrik olguların yaş, cinsiyet, lokalizasyon, histolojik tip ve derecelerine göre dağılımını değerlendirmeyi amaçladık.

Gereç ve Yöntem: Bu çalışmaya 2011 Ocak - 2019 Temmuz ayları arasında Anabilim dalımızda santral sinir sistemi tümörü (SSS) tanısı alan 18 yaş altı 119 çocuk dahil edildi. Klinik takiplerine hastanemiz nükleus sistemi ve pediatrik onkoloji bölüm arşiv dosyaları aracılığıyla ulaşıldı.

Bulgular: Tümör tanısı alan 119 olgunun 57'si (\% 48 ) k1z, 62'si (\% 52) erkekdi. Yaş (0-18) arasında olup vakaların 40'1 (\% 34) $0-5,36$ 'sı (\% 30) $6-10$ ve 43 'ü (\% 36) $11-18$ yaş arasindaydi. Olguların 42'si (\%35.02) posterior fossa lokalizasyonundaydı. En sik astrositomlar izlenmekte olup, astrositomlar1 medulloblastom ve ependimom takip etmektedir. Astrositom vakalarının \%50'sini pilositik astrositom oluşturmaktadır.

Sonuç: Sonuçlarımız literatür bilgileri ile uyumlu olup, çocukluk çağındaki santral sinir sistemi tümörleri lösemilerden sonra en sık görülen tümörler olup sağkalım açısından tümörün tipi, yerleşim yeri, büyüklüğü ve tedavi yöntemleri oldukça önemlidir. Tedavide cerrahi çok önemli role sahip olup, hastaların takipleri ve tedavi modaliteleri (KT ve/veya RT kararı) hasta ve hastalık ile ilişkili analizler yapılıp multidisipliner yaklaşım ile verildiğinde daha iyi sonuçlar elde edilecektir.
\end{abstract}

Anahtar Kelimeler: Santral sinir sistemi tümörleri, Patolojik değerlendirme, WHO 2007 sinıflandırması

\section{Giriş}

Santral sinir sistemi tümörleri (SSS) çocukluk çağında lösemi ve lenfomadan sonra görülen en yaygin tümörlerdir ve pediatrik tümörlerin yaklaşık \%2025'ini SSS tümörleri oluşturmaktadır (1-4). Etyolojide s1klikla genetik, çevresel ve immünolojik faktörler, ionize radyasyon suçlanmaktadır $(2,5)$. Çocukluk çağında en sik astrositomlar izlenmekte onu

\begin{abstract}
Objective: The aim of this study is to evaluate the distribution of pediatric brain tumors diagnosed in our institution according to age, gender, localization, histological type and grade.

Materials and Methods: One hundred and nineteen children under 18 years of age, diagnosed with central nervous system tumor (CNS) in our department between 2011 january -2019 july is included in the study. Clinical follow-up was achieved through the archive files of the hospital data management system and the files of pediatric oncology department.

Results: Of 119 patients who had a tumor diagnosis, 57 $(48 \%)$ were female and $62(52 \%)$ were male. Age distribution was as follows: $40(34 \%)$ cases $0-5,36(30 \%)$ cases $6-10$ and $43(36 \%)$ cases $11-18$ years of age. Fourty-two of the cases had a tumor with posterior fossa localization. Astrocytoma was the most frequent tumor type, followed by medulloblastoma and ependymoma. Fifty percent of the astrocytomas were pilocytic variant.

Conclusion: Our results were accordance with the literature. Childhood central nervous system tumors are the most common tumors after leukemia and the type, location, size and treatment methods of the tumor are very important for survival. Surgery has a very important role in the treatment and better results will be obtained when the follow-up and treatment modalities (CT and / or RT decision) of patients and disease-related analyzes are performed and given with a multidisciplinary approach.
\end{abstract}

Key Words: Central nervous system tumors, Pathological review, WHO 2007 classification

medulloblastom, kraniofarengiom ve ependimomlar takip etmektedir $(1,6)$. SSS tümörleri çocukluk çağında erkeklerde daha sık izlenmektedir $(5,6)$. SSS tümörleri sınıflandırılmasında Dünya Sağlık Örgütü (DSÖ) sınıflandırması kullanılmaktadır (4-7). DSÖ tarafından beyin tümörleri köken aldıkları hücre tipine göre sinıflandırılmaktadır. Sinıflamada tümörler; varyantları ve morfolojik özellikleri, klinik, radyolojik ve genetik özellikleri ile birlikte verilmektedir. Ayrıca

*Sorumlu Yazar: Dr Bermal Hasbay, Başkent Üniversitesi Adana Dr. Turgut Noyan uygulama ve Araştırma Merkezi, Dadaloğlu mah. 2591 sok. No:4/A Yüreğir/Adana

E-mail: bermalhasbay@hotmail.com, Tel: 0 (505)6247028

ORCID ID: Bermal Hasbay: 0000-0002-7941-7962, Fazilet Kayaselçuk: 0000-0002-1180-3840, Özgür Kardeş: 0000-0003-2854-941X,

Nalan Yaz1c1: 0000-0003-4465-8229

Geliş Tarihi: 14.02 .2019 , Kabul Tarihi: 12.06 .2020 
tümörler differansiyasyon ve artan malignite derecesine göre 1-4 arasında derecelenmektedir (5). Çalışmamızda olguların histolojik derecelendirmesi 2007 Dünya sağlık örgütü SSS tümörleri sınıflaması temel alınarak yapıldı. DSÖ 2016 yilında SSS tümörlerini morfoloji yanı sıra moleküler özelliklerini de içeren entegre bir sistemle yeniden sınıflandırmıștır. 2007 DSÖ sınıflaması tümörlerin moleküler özelliklerini içermekle birlikte bunlar tanı kriteri olarak kullanılmamaktaydı (5). Çalışmamız retrospektif bir arşiv taraması olduğundan, olgularımız 2007 sinıflamasına göre yapıldı.

$\mathrm{Bu}$ çalışma ile 18 yaş altı beyin tümörü tanısı alan hastalarımızın histopatolojik tanısı, grade'i, sağ kalım verileri değerlendirilmiş olup bundan sonraki yıllar hem tedavi, hemde izlem protokolleri konusunda veri elde edilmiştir.

Retrospektif olarak beyin tümörlerinin epidemiyolojik ve histolojik olarak irdelenmesi özellikle gelecek araştırmalar için önemlidir. Çünkü bir popülasyonun tümör spektrumundaki değişiklikleri göstermesi, risk faktörlerini belirleme ve potansiyel terapi metodlarının gelişimini belirleme açısından oldukça değerlidir.

$\mathrm{Bu}$ amaçla hastanemizde çocukluk çağında SSS tümörü tanısı alan olgularımızın, patolojilerini WHO 2007 sinıflamasina göre klasifiye etmeyi ve tedavi ile prognostik sonuçlarını retrospektif olarak değerlendirmeyi amaçladık.

\section{Gereç ve Yöntem}

Çalısmaya 2011 Ocak -2019 Temmuz ayları arasında hastanemiz Patoloji A.D arşivi gözden geçirilerek 18 yaş ve altında beyin tümör tanısı alan toplam 119 adet vaka alındı. Tüm tümörler 2007 DSÖ sinıflamasina göre değerlendirildi ve derecelendirildi. Olguların klinik izlemleri hastanemiz nükleus sistemi ve pediatrik nöro-onkoloji grubu kayıt arşivinden elde edildi.

Takibimizde olan 95 hastanın verilerinin istatistiksel analizinde SPSS 17.0 paket programı kullanıldı. Kategorik ölçümler sayı ve yüzde olarak, sürekli ölçümlerse ortalama ve standart sapma (gerekli yerlerde ortanca ve minimum - maksimum) olarak özetlendi. Sağ kalım eğrisi için Kaplan-Meier yöntemi ve gruplar arasındaki sağ kalım farklılıklarını hesaplamak için Log-rank testi uyguland. Tüm testlerde istatistiksel önem düzeyi 0.05 olarak alındı.

$\mathrm{Bu}$ çalışma Başkent Üniversitesi Tip ve Sağlık Bilimleri Araştırma Kurulu tarafindan onaylanmış (Proje No: KA19/343)'dır.

\section{Bulgular}

Olguların çoğu başağrısı, kusma şikayetiyle kliniğe başvurmuş olup, daha az oranda nöbet geçirme, yürümede dengesizlik, bacaklarda güçsüzlük ve gözlerde kayma şikayeti mevcuttu.

Tümör tanis1 alan 119 olgunun 57'si (\%48) k1z, 62'si (\%52) erkekti. Yaşları 0-18 arasında (ortalama $8.7 \pm$ 4.5) değişmekteydi. Vakaların 40'1 (\%34) 0-5, 36's1 (\%30) 6-10, 43”ü (\%36) 11-18 yaş arasındaydı. Takip süresi 1-152 ay arasında değişmekte olup, ortalama 32 ay'dır. Olguların 42'si (\%35.02) posterior fossa lokalizasyonundaydı. Vakalarımızın 2007 DSÖ sınıflamasına göre dağılımı Tablo 1'de verilmektedir. En sik astrositomlar sonra sirasiyla medulloblastom ve ependimom takip etmektedir. Astrositom vakalarının $\% 50$ 'sini pilositik astrositom oluşturmaktadır (Tablo 1).

Olguların 24'ü takibimizden çıkmış olup bu olguların beşi tanıdan 6 ay, dokuzu 1 yll, ikisi 2 yll hastanemizde tedavi alıp sonra takibimizden çıkmıştır. Diğgr sekiz vaka bölümümüzde tanı alıp, tedaviye başlanmamıştır. Takip edilen 95 olgunun 15’i (\%16) ex olmuş, diğer $80(\% 84)$ olgu halen takibimizdedir. Takibimizden çıan hastalardan üçü ex, 20'si yaşıyor, biri yabancı uyruklu olduğundan dolayı nüfus bilgisine ulaşılamadı. Ex olan hastalar takimizden çıktıktan 7, 20 ve 34 ay sonra ex olmuşlardır.

Takipli hastalarımızdan ex olan 15 olgunun ikisi anaplastik astrositom, biri atipik teratoid rabdoid tümör (ATRT), dördü ependimom, üçü glioblastome multiforme (GBM), üçü medulloblastom, biri menengiom ve biri metastatik mikst germ hücreli tümördür. Ex olan olgularımızın 10'u 0-10 yaş arası, beşi 11-18 yaş arasındadır. Menengiom olgusu dört yıl önce dış merkezde tanı almış ve üç kez nüks nedeniyle diş merkezde opere olmuş ve daha sonra dördüncü kez nüks nedeniyle hastanemize başvurmuş ve 1 ay sonra ex olmuştur. Olgularımızın 111'i (\%93) WHO 2007 sınıflamasına göre grade'lenmiş olup Tablo 2'de sıklık, cinsiyet ve yaşam-ex skalası özetlenmiştir.

Genel sağ kalım ortalama yaşam süresi $118.9 \pm 6.9$ ay olup , ( 95 \% CI 105.3-132.5); bir yillık sağ kalım \%88.5 ve beş yıllık sağ kalım \% 75.6 oranındadır (Şekil 1).

Yaş gruplarına göre (0-5 / 6-10/ 11 yaş ve üstü) ve cinsiyete göre bakıldığında beklenen yaşam süreleri arasinda fark izlenmedi (Sirasiyla $\mathrm{P}=0.880$ ve $\mathrm{P}=0.971$ Log-rank test). Grade'e göre bakıldığında grade 1 ve grade 2 hastalar arasinda ex olan vaka saptanmadi. Grade 3 olan olgularımızda bir yıllık tahmini yaşam süresi \%62.6 iken beş ylllk \%45.7'di. Grade 4 hastalar arasında bir y1llık \%88.6 iken, beş yllık \%66.6 olarak 
Tablo 1. Vakalarımızın 2007 DSÖ sınıflamasına göre sıklık ve grade’ine göre dağılımı

\begin{tabular}{|c|c|c|}
\hline & Grade 1 Pilositik astrositom 24 & $\% 20.1$ \\
\hline & Düşük dereceli glial tümör 6 & $\% 5.1$ \\
\hline & Grade 2 Diffüz astrositomlar 4 & $\% 3.4$ \\
\hline \multirow[t]{4}{*}{ Astrositik tümörler 46 vaka (\%38.7) } & Pilomiksoid astrositom 2 & $\% 1.7$ \\
\hline & Grade 3 Anaplastik astrositomlar 2 & $\% 1.7$ \\
\hline & Pleomorfik ksantoastrositom 1 & $\% 0.8$ \\
\hline & Grade 4 Glioblastom 7 & $\% 5.9$ \\
\hline \multirow[t]{2}{*}{ Oligodendroglial tümör 2 vaka $(\% 1.7)$} & Grade 2 Oligodendrogliom 2 & $\% 1.7$ \\
\hline & Grade 1 Miksopapiller ependimom 1 & $\% 0.8$ \\
\hline \multirow[t]{2}{*}{ Ependimal tümörler 19 vaka \%15.9) } & Grade 2 Ependimom 2 & $\% 1.7$ \\
\hline & Grade 3 Anaplastik ependimom 16 & $\% 13.4$ \\
\hline \multirow[t]{3}{*}{ Embriyonel Tümörler 32 vaka ( \%26.9) } & Grade 4 Medulloblastom 27 & $\% 22.7$ \\
\hline & Grade 4 Atipik teratoid / rabdoid tümör 5 & $\% 4.2$ \\
\hline & Grade 1 Gangliogliom 3 & $\% 2.7$ \\
\hline \multirow[t]{4}{*}{ Diğer Nöroepitelyal tümörler 6 (\%5.1) } & Grade 2 Pineositom 1 & $\% 0.8$ \\
\hline & Grade 2 Santral nörositoma 1 & $\% 0.8$ \\
\hline & Grade 4 Pineoblastom 1 & $\% 0.8$ \\
\hline & Germinom 1 & $\% 0.8$ \\
\hline \multirow[t]{3}{*}{ Germ hücreli tümör 5 vaka (\% 4.2) } & Teratom 2 & $\% 1.7$ \\
\hline & Mikst germ hücreli tümör 2 & $\% 1.7$ \\
\hline & Menengiom 5 & $\% 4.2$ \\
\hline \multirow[t]{3}{*}{ Diğer Tümörler 9 vaka (\% 7.5) } & Kraniofrangioma 2 & $\% 1.7$ \\
\hline & $\mathrm{B}$ hücreli lenfoma 1 & $\% 0.8$ \\
\hline & Adenom 1 & $\% 0.8$ \\
\hline
\end{tabular}

Tablo 2. Grade’i Yapılan 111 Olgunun Sıklı̆g1

\begin{tabular}{lccccc}
\hline Grade & S1klı̆̆ & Kız & Erkek & Yaşam & Ex \\
\hline Grade 1 & $38(\% 34.2)$ & 21 & 17 & 38 & - \\
Grade 2 & $11(\% 9.9)$ & 4 & 7 & 11 & - \\
Grade 3 & $22(\% 19.8)$ & 11 & 11 & 16 & 6 \\
Grade 4 & $40(\% 36.1)$ & 20 & 20 & 32 & 8 \\
\hline
\end{tabular}

saptanmış olup grade göre yaşam süreleri arasında fark mevcuttu ( $\mathrm{p}=0.001$ log-rank test) (Şekil 2).

Ayrica en s1k görülen tümörlerden medulloblastom, pilositik astrositom ve ependimom hastalarının bir yıllık sağ kalım oranları sırasıyla \%95.7, \%100 ve $\% 74.7$ iken beş yıllık să̆ kalım oranları sırasıyla $\% 78.1, \% 100$ ve $\% 64$ olarak saptand. Ex olan hastalarımızın takip süreleri Tablo 3'de özetlenmiş olup 1-43 ay arasında değişmektedir.

\section{Tartışma}

Santral sinir sistemi (SSS) tümörleri çocukluk çağında lösemilerden sonra 2. en s1k izlenen tümör grubu olmakla birlikte kanserden ölümlerin çoğunluğunu oluşturmaktadır (1-4).
SSS tümörleri çocukluk çağında erkeklerde daha sık izlenmekte olup çalışmamızda da erkeklerde (\%52) daha sık saptanmıştır.

Çocukluk çağında en sık astrositomlar izlenmekte onu medulloblastom, kraniofarengiom ve ependimomlar takip etmektedir $(1,6,8,9,10)$. Örneğin Almanya'da en s1k astrositom ve ependimom izlenirken, komşu ülkelerimizden İran'da en sik medulloblastom, gliom ve ependimom, Suriye'de ise en s1k medulloblastom izlenmekte olup kroniofarengioma görülme oranı da yüksek izlenmektedir $(6,9)$. Bölgemizde bulunan bir diğer hastanenin yaptığ 1 çalışmada en çok medulloblastom izlenirken onu astrositom ve ependimom takip etmektedir(11). Bizim çalışmamızda en s1k astrositom, medulloblastom ve ependimom izlenmekte, ancak kraniofarengioma daha az s1klikta 
Tablo 3. Ex olan hastalarımızın takip süreleri

\begin{tabular}{lcc}
\hline Tümör ad1 & Grade & Takip süresi \\
\hline Anaplastik astrositom & 3 & 5 ay \\
Anaplastik astrositom & 3 & 8 ay \\
GBM & 4 & 22 ay \\
GBM & 4 & 1 ay \\
GBM & 4 & 2 günü ex \\
GBM & 4 & 19 ay \\
Medulloblastom & 4 & 43 ay \\
Medulloblastom & 4 & 16 ay \\
Medulloblastom & 4 & 11 ay \\
Ependimom & 3 & 11 ay \\
Ependimom & 3 & 29 ay \\
Ependimom & 3 & 8 ay \\
Metastatik mikst germ hücreli tümör & - & 2 ay \\
ATRT & 4 & 1 ay \\
Menengiom & 3 & 1 ay \\
\hline
\end{tabular}

GBM: Glioblastome Multiforme

ATRT: Atipik teratoid rabdoid tümör

Survival Function

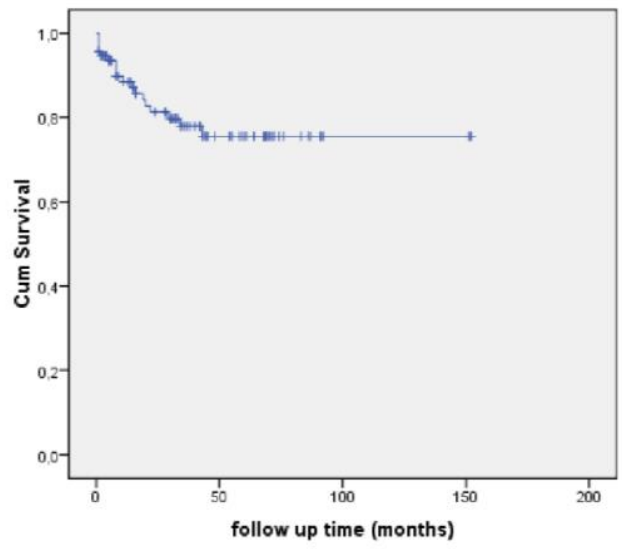

Şekil 1.5 yıllık tahmini sağ kalım grafiği

izlenmektedir. Olgularımız arasında kraniofarengioma tanısının az olması hastanemizin bölgemizde önemli bir referans merkezi olması ve yüksek dereceli tümörlerin hastanemize yönlendirilmesi önemli bir etken olabilir.

Çocukluk çağında SSS tümörleri sıklıkla çalışmamızda olduğu gibi posterior fossa lokalizasyonunda izlenmektedir $(1,2,6)$.

Semptom ve bulgular tümörün yerleşim yerine, yaşına ve histolojisine göre değişmektedir. Beyin tümörleri çevre SSS yapılarını infiltre ederek yada BOS yollarında obstrüksiyona yol açıp intrakranial basınç artışına yol açarak nörolojik bozukluk meydana getirirler. Intrakranial basınç artışıda klinik bulguların ortaya çıkmasına sebep olur. Bu bulgular baş ağr1sı, kusma, huzursuzluktur. Süt çocukluğu döneminde

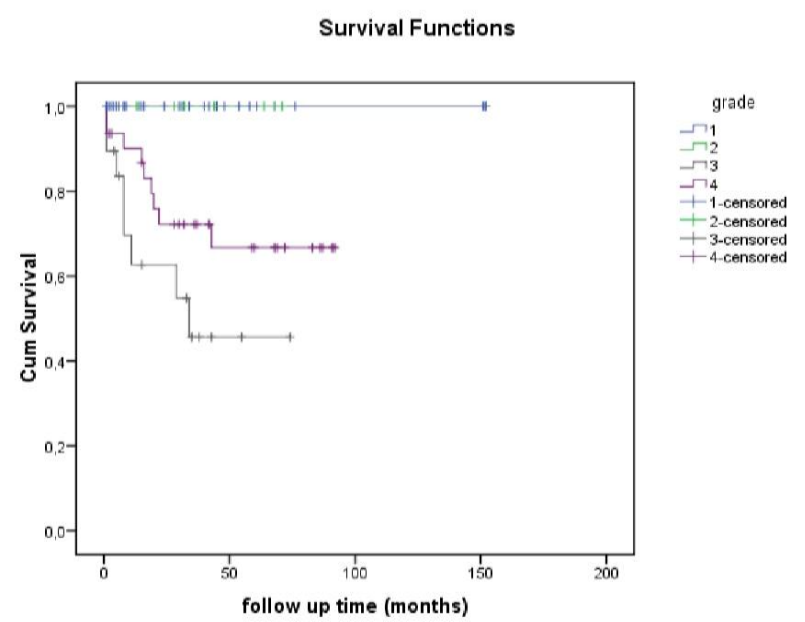

Şekil 2. Grade’e göre sağ kalım grafiği

sıklıkla huzursuzluk, kusma ve gelişme geriliği gibi bulgular ön plandayken, daha ileri yaşlarda baş ağrısı, kusma ve nöbetler en s1k yakınma olabilir $(2,5,10)$. Olgularımızın çoğu başağrısı, kusma şikayetiyle kliniğe başvururken, onu nöbet geçirme, yürümede dengesizlik, bacaklarda güçsüzlük ve gözlerde kayma şikayeti takip etmektedir. Medulloblastom tanilı hastalarımız en sık kusma, baş ağrısı ve yürümede dengesizlik şikayetiyle başvururken, ependimom tanılı hastalarımız baş ağrısı, baş dönmesi ve kusma şikayetiyle kliniğe başvurmuşlardır.

SSS tümörleri özellikle son 20 yllda tüm dünyada (yaklaşık \%40) hızlı bir şekilde artmakta olup, her y1l dünya çapında yaklaşık 30000-40000 yeni vaka tanı almaktadır $(9,12)$. Bizim çalışmamızda yıllara göre artış izlenmemektedir. Çocukluk çağında metastatik 
santral sinir sistemi tümörleri oldukça azdır, çalışmamızda 18 yaşında bir olguda testis kaynaklı germ hücreli tümör metastazı saptanmıştır.

Çalışmamızda tümör derecesi ve yaş arasında istatistiksel bir ilişki saptanmadi. Olgularımızın takipleri 1 ay ve 152 ay arasında değişmektedir. En uzun süreli takip ettiğimiz olgu Pilositik astrositom olup 152 aydir takipdedir. Medulloblastom hastalarımız 2-92 aydır takipde olup, ependimom hastalarımı 1-74 ay takipdedir.

Amerika Birleşik Devletleri kanser istatistik programı verilerine göre 1975-1979 y1lları arasında genel sağ kalım \%59 iken, 2003-2009 yilları arasinda \%75'e yükselmiştir. Alt gruplara göre beş yıllık sağ kalım ependimomda \%37'den \%81'e, astrositomda \%69'dan $\% 85$ 'e ve medulloblastomda ise \%47'den \%70'e yükseldiği bildirilmiştir (13). Hastanemizde medulloblastom hastalarımızın 5 yıllık genel sağ kalımı $\% 78.1$, ependimomun ise \%64 olarak izlendi. Çalışmamızda yaş, cinsiyet, histopatolojik tipler ve genel sağ kalım oranları literatür ile uyumlu olarak izlenmiştir.

Mortalite oranları yapılan çalışmalarda tümör grade’i (yüksek grade'li tümörler: medulloblastom, glioblastome multiforme, atipik teratoid/rabdoid tümör ve anaplastik ependimomlar) hastanın yaşı ve tümör lokalizasyonuyla ilişkilidir $(10,14,15)$. Örneğin ependimomlarda özellikle beş yaş altında prognozun beş yaş üstündekilere göre daha kötü olduğunu belirten çalışmalar mevcut olduğu gibi, yaşın prognoza etkisinin olmadığını öne süren çalışmalarda bulunmaktadır. Bizim çalışmamızda da ex olan 15 olgumuz yüksek grade'li ve yaşları çoğunlukla 0-10 yaş arasinda izlenmektedir.

Retrospektif olarak beyin tümörlerinin epidemiyolojik ve histolojik olarak irdelenmesi özellikle gelecek araştırmalar için önemlidir. Çünkü bir popülasyonun tümör spektrumundaki değişiklikleri göstermesi, risk faktörlerini belirleme ve potansiyel terapi metodlarının gelişimini belirleme açısından oldukça değerlidir.

Çocukluk çağ1 SSS’i tümörlerinin yönetiminde hastaların yaşam kalitesinin iyi olması ve sağ kalımın artması için Beyin cerrahisi, Çocuk Onkoloji, Patoloji, Radyoloji, Çocuk Endokrin, Çocuk Nöroloji ve Radyasyon Onkolojisi bölümleri ortak görev almaları çok büyük öneme sahiptir.

Son y1llarda klasik morfolojik bulgular yanı sira moleküler patolojideki ilerlemeler sonucunda özellikle medulloblastom ve ependimomlarda histopatolojik sinıflamaya ek olarak moleküler sinıflandırmada yapilmaktadir $(5,16,17)$.

Çalışmamız retrospektif bir çalışma olduğundan moleküler sinıflandırmanın yapılamaması bir eksikliğimizdir. Ancak doğru histopatolojik tanımlama, tümör derecesi, rezeksiyonun şekli, yaş ve yerleşim yeri ve prognozların belirlenmesi, moleküler çalışmalar ile hastaların tedavi ve takip modaliteleri açısından oldukça önemlidir.

$\mathrm{Bu}$ çalışmanın sonuçları Türkiye'deki 18 yaş altı çocuklarda izlenen beyin tümörlerinin oranını tam olarak açıklamasa da büyük oranda yansıtmaktadır. Çünkü hastanemiz bölgemizdeki büyük birkaç onkoloji merkezinden biri olması nedeniyle hastalarımızın histolojik tanıları ve sağ kalım hızları değerlendirilmesinin ülkemiz ve bölgemizdeki diğer merkezlere 1şık tutacağını düşünmekteyiz.

Sonuç olarak çalışmamızda SSS tümörleri en s1k posterior fossa lokalizasyonunda izlenmiş olup, en s1k pilositik astrositom izlenirken onu medulloblastom ve ependimom takip etmektedir. Erkeklerde daha s1k izlenmektedir. Genel sağkalım tümör tipi, biyolojisi, yerleşim yeri, takip ve tedavi yöntemleri oldukça önemlidir. Tedavide cerrahi çok önemli role sahip olup, hastaların takipleri ve tedavi modaliteleri (KT ve/veya RT kararı) hasta ve hastalık ile ilişkili analizler yapılıp multidisipliner yaklaşım ile verildiğinde daha iyi sonuçlar elde edilecektir.

\section{Kaynaklar}

1. Shah SH, Soomro IN, Hussiny AS, Hassan SH. Clinico-morphological pattern of intracranial tumors in children. J Pak Med Assoc 1999; 49 (3): 63-65.

2. Demirkaya M, Sevinir B. Çocukluk çağ beyin tümörleri. Güncel Pediatri 2005; 3 (1): 118-121.

3. Missaoui N, Khouzemi M, Landolsi H, Jaidene L, Abdelkrim SB, Abdelkader AB. Childhood cancer freguency in the center of tunisia. Asian Pasific Journal of Cancer Prevention 2011; 12 (2): 537-542.

4. Sexton-Oates A, MacGregor D, Dodgshun A, Saffery R. The potential for epigenetic analysis of pediatric cns tumours to improve diagnosis, treatment and prognosis. Annals of Oncology 2015; 26 (7): 1314-1324.

5. Louis DN, Ohgaki H, Wiestler OD, Cavenee WK. Tumors of the central nervous system. pathology and genetics: World Health Organization İnternational Classification of Tumours. Lyon, France: IAR; 2007.

6. Katchy KC, Alexander S, Mohammed AN, AlRamadan A. Epidemiology of primary brain tumors in childhood and adolescence in kuwait. Springer Plus 2013; 2(1): 58.

7. Aygün MS, Aygün FM. Çocukluk çağ1 beyin tümörleri. Selçuk Pediatri Derleme 2014; 2(1): 618.

8. Chen L, Zou X, Wang Y, Mao Y, Zhou L. Central nervous system tumors: a single center 
pathology review of 34.140 cases over 60 years. BMC Clinical Pathology 2013; 13 (1): 14.

9. Ezzat S, Kamal M, El-khateeb N, El- Beltagy M, Taha H. Pediatric brain tumors in a low/middle income country: does it differ from that in developed world. J. Neurooncol 2016; 126 (2): 371-376.

10. Pinho RS, Androni S, Silva NS, Cappellano A, Masruha M. Pediatric central nervous system tumors: A single -center experience from 1989 to 2009. J. Pediatric Hematol Oncol 2011; 33 (8): 605-609.

11. Küpeli BY, Ökten AH, Gezercan Y, Uluç Ş, Menteş S. Çocukluk çă̆1 santral sinir sistemi tümörleri: 60 olgunun retrospektif analizi. Çukurova Medical Journal 2018; 43(4): 931-935.

12. Zahir ST, Vakili M, Navabii H, Rahmani K. Clinico pathological findings and five year survival rates for patients with central nervous system tumors in yazd 1ran. Asian Pac J Cancer Prev 2015; 15 (23): 10319-10323.

13. Ward E, Desantis C, Robbins A, Kohler B, Jemal A. Childhood and adolescent cancer statistic. CA Cancer J Clin 2014; 64 (2): 83-103.

14. Rickert $\mathrm{CH}$, Paulus W. Epidemiology of central nervous system tumors in childhood and adolescence based on the new who classification. Childs Nerv Syst 2001; 17 (9): 503-511.

15. Kaatsch P, Rickert $\mathrm{CH}$, Kuhl J, et al. Population based epidemiologic data on brain tumors in german children. Cancer 2001; 92 (12): 31553164.

16. Çomunoğlu N, Öz B. Medulloblastom. Türkiye Klinikleri J Med Pathol-Special Topics 2016; 1(2): 48-57.

17. Uyar Bozkurt S. Ependimal Tümörlerde Patogenez, Histolojik ve Moleküler Güncel Yaklaşımlar. Türkiye Klinikleri J Med PatholSpecial Topics 2016; 1(2): 30-37. 